\title{
BMJ Open Multivariate analysis of the impact of weather and air pollution on emergency department visits for night-time headaches among children: retrospective, clinical observational study
}

To cite: Yamaguchi H, Nozu K, Ishiko S, et al. Multivariate analysis of the impact of weather and air pollution on emergency department visits for night-time headaches among children: retrospective, clinical observational study. BMJ Open 2021;11:e046520. doi:10.1136/ bmjopen-2020-046520

- Prepublication history for this paper is available online. To view these files, please visit the journal online (http://dx.doi. org/10.1136/bmjopen-2020046520).

Received 02 November 2020 Revised 23 February 2021 Accepted 29 March 2021

Check for updates

(c) Author(s) (or their employer(s)) 2021. Re-use permitted under CC BY-NC. No commercial re-use. See rights and permissions. Published by BMJ.

${ }^{1}$ Department of Pediatrics, Kobe University Graduate School of Medicine, Kobe, Hyogo, Japan ${ }^{2}$ Kobe Children's Primary Emergency Medical Center, Kobe, Hyogo, Japan ${ }^{3}$ Nihon University School of Medicine Graduate School of Medicine, Itabashi-ku, Tokyo, Japan

Correspondence to Dr Hiroshi Yamaguchi; hiyamagu@med.kobe-u.ac.jp

\section{ABSTRACT}

Objectives To examine the association between the number of visits to the emergency department (ED) by children for night-time headaches and exposure to multifaceted factors, such as meteorological conditions and air pollution.

Design We conducted a clinical observational time-series analysis study.

Setting We reviewed consecutive patients younger than 16 years of age at the primary ED centre in Kobe city, Japan, during the night shift (19:30-7:00 hours) between 1 January 2011 and 31 December 2019.

Participants In total, 265191 children visited the ED; 822 presented with headache during the study period.

Primary outcome measures We investigated the effects of meteorological factors and air pollutants by multivariate analysis of Poisson regression estimates. A subanalysis included the relationship between the number of patients with night-time headaches and the above factors by sex. Furthermore, the effect of typhoon landing on patient visits for headache was also analysed. Headache was not classified because examinations were performed by general paediatricians (non-specialists).

Results The number of patients with night-time headaches displayed distinct seasonal changes, with peaks during the summer. Multivariate analysis of Poisson regression estimates revealed a significant positive relationship between the number of patients for headache and mean temperature. Subanalysis by sex indicated a positive relationship between the number of patients with headache and mean temperature in both sexes; however, it was significant only for females. No relationship was found between the number of patients with headache and air pollution. There was no change in the number of patients for night-time headaches 3 days before and after typhoon landing.

Conclusions High temperature is the main factor for visiting ED for night-time headaches among children in Kobe city. Our results suggest that preventive measures against night-time headaches may be possible by reducing time spent outside during summer.
Strengths and limitations of this study

A large number of participants were included

- The study period was long (9years).

- Many environmental factors were analysed.

- Headache was not classified.

- Regarding air pollutants, the data of only one centre were chosen, and it may differ from the actual environment of each patient.

\section{INTRODUCTION}

Headache is one of the most common reasons for emergency department (ED) visits among children. ${ }^{1}$ A systematic review reported that around $60 \%$ of population experience a headache at least once in their life. ${ }^{2}$ In addition, an increase in the frequency of paediatric ED visits for headache has been reported. ${ }^{3}$ Therefore, investigating the factors that contribute to ED visits by paediatric patients seems to be very useful for prevention and prediction. Air pollutants, such as sulphur dioxide $\left(\mathrm{SO}_{2}\right)$, nitrogen dioxide $\left(\mathrm{NO}_{2}\right)$, carbon oxide $(\mathrm{CO})$, ozone $\left(\mathrm{O}_{3}\right)$, and particulate matter $(\mathrm{PM}),{ }^{4-10}$ and weather parameters, such as ambient temperature, atmospheric pressure, relative humidity and wind speed, have been reported as environmental factors for headache in all age groups. ${ }^{810-15}$

For many decades, many epidemiological studies have examined the association between environmental factors and headache among adults or all age groups. However, to the best of our knowledge, there have been a few studies on the effects of air pollutants or weather parameters on ED visits for headache focusing on children, ${ }^{11}$ and there have been no reports of the relationship between 
environmental factors and ED visits for night-time headaches.

The aim of the present study was to examine the association between the number of visits by children to the ED during the night for headache (night-time headaches) and exposure to multi-faceted factors, such as meteorological factors and air pollution, after controlling for confounding factors. As a sub-analysis, we analysed the relationship between the number of patients presenting with night-time headaches and the above factors by sex. In addition, we also analysed the effects of typhoons on the number of patients presenting with night-time headaches because typhoons arrive from summer to autumn in Japan and there is a long-standing belief that typhoon landing is associated with headache frequency.

\section{PATIENTS AND METHODS}

\section{Study design and patients}

This study was performed in Kobe city, Japan. Kobe city is located on the southern part of the main island of Japan, with approximately 1500000 residents, 200000 of whom are children younger than 16 years old. We reviewed the clinical database of consecutive patients aged younger than 16 years at the ED of Kobe Children's Primary Emergency Medical Center, the largest night-time emergency medical centre in the Hyogo prefecture in Japan between 1 January 2011 and 31 December 2019. Kobe Children's Primary Emergency Medical Center provides medical services for paediatric patients during holidays and outside of regular working hours (19:30-7:00 hour). Approximately 30000 paediatric patients per year visit this centre, which covers $50 \%-60 \%$ of all primary emergency patients in Kobe city. The data included information on patients' sex, age, diagnosis and date of visit. In total, 265191 children visited the centre during the study period, and a total of 822 children who visited the centre for headache during the night shift (19:30-7:00 hour) were included in the present study. That is, consecutive paediatric patients with a primary diagnosis of headache (International Classification of Disease, $10^{\text {th }}$ revision code R51) were included in this study. Headache was not classified because examinations were performed by general paediatricians (non-specialists).

\section{Patient and public involvement}

The factors involved in night-time headache among children remain unknown. For public health, the study questions described above are highly relevant and have a high priority given the frequency of ED visits for night-time headache among children. This research did not include the recruitment of patients, but rather used data from participants who visited Kobe City Public Health Center for night-time headache. The public was not invited to comment on the study design and was not consulted in the development of relevant outcomes or for the interpretation of results. Study results will be published in peer-reviewed journals and communicated to the public by the participating authors.

\section{Meteorological data}

Meteorological data of Kobe city for the study period were retrieved from the Japan Meteorology Agency (https://www.jma.go.jp/jma/indexe.html). The agency officially releases hourly, monthly and yearly meteorological data for Kobe city online. The data included atmospheric pressure $(\mathrm{hPa})$, precipitation $(\mathrm{mm})$, temperature $\left({ }^{\circ} \mathrm{C}\right)$, relative humidity $(\%)$, wind speed $(\mathrm{m} / \mathrm{s})$ and hours of sunlight (hour). The days of typhoon landing were retrieved from the Japan Meteorology Agency (https:// www.data.jma.go.jp/fcd/yoho/typhoon/statistics/index. html).

\section{Air pollutants data}

Air pollutant data were retrieved daily from the air pollution monitoring station of Hyogo Nanbu Taiki Sokutei Kyoku during the study period (http://kobe-taikikanshi. $\mathrm{jp} / \mathrm{kankyo} /$ ). The station is one of the main stations in Kobe city $(6.05 \mathrm{~km}$ from our medical centre). The station collects pollution measures hourly. The data monitored included $\mathrm{SO}_{2}$, nitrogen oxide $(\mathrm{NO}), \mathrm{NO}_{2}$, nitrogen oxides (NOX), oxidant (OX), methane $\left(\mathrm{CH}_{4}\right)$, nonmethane hydrocarbons (NMHC), total hydrocarbons (THC), suspended particulate matter (SPM; PM $\leqq 10 \mu \mathrm{m})$, and fine $\mathrm{PM}\left(\mathrm{PM}_{2.5}\right), \mathrm{PM}_{2.5}$ measurements began on 30 July 2012. Therefore, $\mathrm{PM}_{2.5}$ data were included thereafter. Daily observations of Asian dust were retrieved from the Kobe City General Call Center (https://www.city.kobe. lg.jp/a66324/kurashi/recycle/kankyohozen/air/kousa. html).

\section{Statistics}

The results are expressed as the mean (SD). Correlations were analysed using Pearson's correlation coefficient. Analyses were performed using GraphPad Prism V.5.0 (GraphPad Software, San Diego, California, USA). Multivariate analysis of Poisson regression estimates using a generalised linear model was performed using EZR (V.1.50), which is a graphical user interface for R (The R Foundation for Statistical Computing) based on $\mathrm{R}$ commander. It adds a variety of statistical functions to the R commander and enables point-and-click easy access to statistical functions, especially for medical statistics and is used widely for medical statistics. ${ }^{16} \mathrm{~A} p<0.05$ was considered statistically significant.

\section{RESULTS}

\section{Patient demographics}

During the study period (2011-2019), children aged younger than 16 years visited our ED during the night for headache and the mean $\pm \mathrm{SD}$ age was $9.0 \pm 3.3$ years. As for sex, $53.6 \%$ were boys $(n=441)$ and $46.4 \%$ were girls $(\mathrm{n}=381)$. 

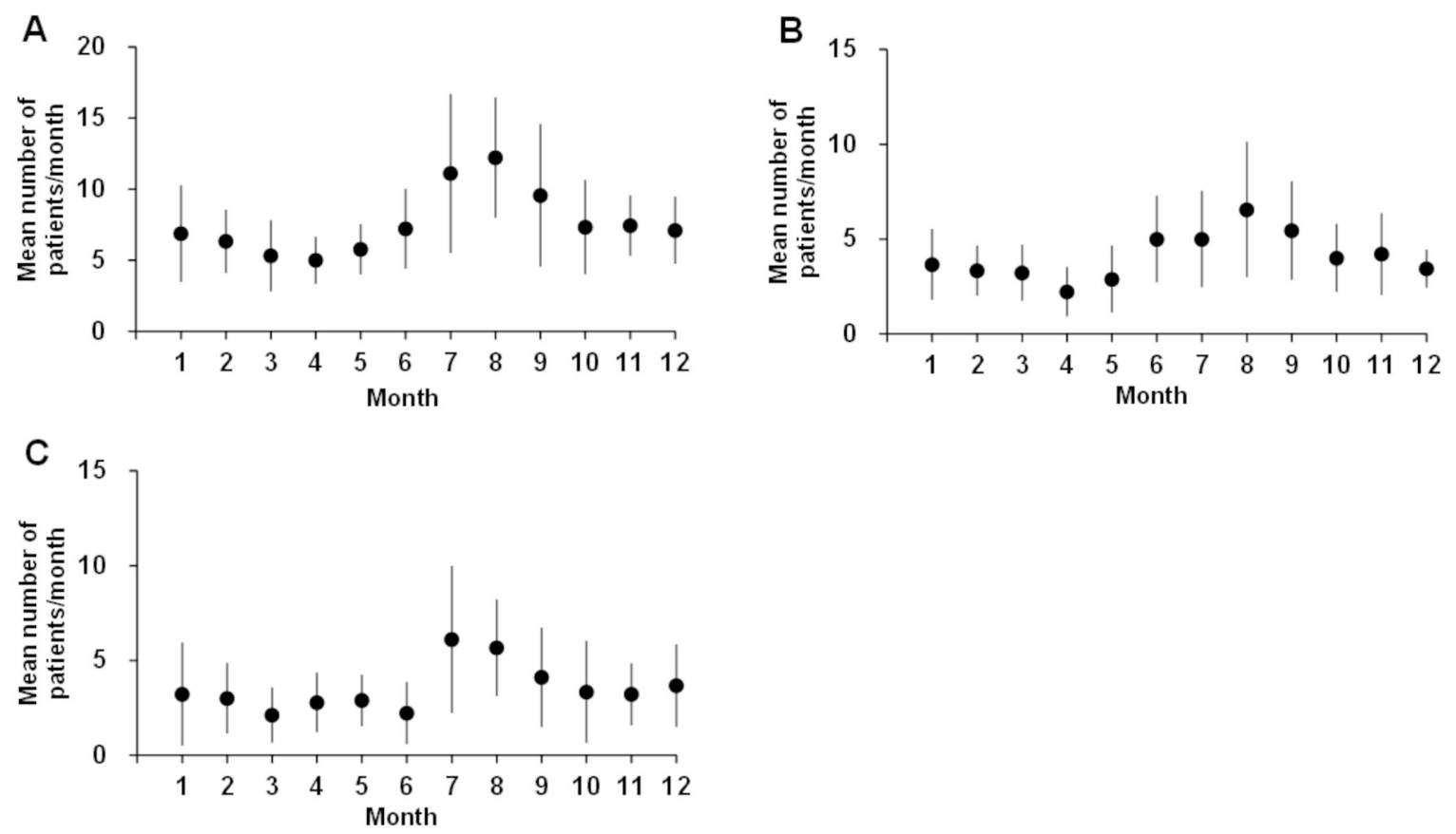

Figure 1 Observed numbers of emergency department visits for headache among children per month as a function of time. (A) total population; $(B)$ male patients and $(C)$ female patients. Data are represented as mean $\pm S D$.

\section{The monthly changes in the number of patients for night-time headaches in Kobe, Japan}

The monthly changes in the number of patients with headache during the night are shown in figure 1 . The number of patients with headache in total varied distinctly according to the season, and there were dominant peaks during the summer (August) and fewer visits during the spring (April) (figure 1A). Subanalysis revealed that there were dominant peaks in the number of patients for night-time headaches during the summer (August) and fewer visits during the spring (April) in male patients (figure 1B). Among female patients, there were also dominant peaks of the number of patients for night-time headaches during summer (July) and fewer during spring (March) (figure 1C). Interestingly, the maximum and minimum number of patients for night-time headaches occurred a month earlier for female than male patients.

\section{Background of environmental factors}

Seasonal mean values of meteorological factors and air pollutants are shown in table 1.

The four seasonal mean values of each factor were calculated. The mean atmospheric pressure was high in winter and low in summer. In contrast, the mean values of precipitation and relative humidity were high in summer and low in winter. The average temperature ranged from $7.0^{\circ} \mathrm{C}$ (winter) to $26.6^{\circ} \mathrm{C}$ (summer). Hours of sunlight were the longest in spring and the shortest in winter. The average wind speed did not fluctuate noticeably.

Air pollutant variables in Kobe, Japan during the study period are shown in table 1 . Seasonal air pollutant variables that were highest during spring, summer and winter were $\mathrm{NO}_{2}, \mathrm{OX}$, and $\mathrm{PM}_{2.5} ; \mathrm{SO}_{2}$ and $\mathrm{SPM}$; and $\mathrm{NO}, \mathrm{NOX}$,
$\mathrm{CH}_{4}, \mathrm{NMHC}$ and THC, respectively. Seasonal air pollutant variables that were lowest during summer, fall and winter were $\mathrm{NO}_{2}, \mathrm{NOX}, \mathrm{CH}_{4}, \mathrm{NMHC}$, and THC; $\mathrm{SO}_{2}, \mathrm{NO}$, and $\mathrm{PM}_{2.5}$; and $\mathrm{OX}$ and SPM, respectively.

\section{Association between night-time headaches and environmental factors}

Pearson correlation coefficients between the environmental variables are shown in table 2 . Significant correlations (Pearson's $r>0.8$ ) were observed between average temperature and highest and lowest temperature, highest and lowest temperature, $\mathrm{NO}$ and $\mathrm{NO}_{2}$ and $\mathrm{NOX}$, NOX and NMHC, NMHC and THC, and SPM and $\mathrm{PM}_{25}$. The multivariate analysis of Poisson regression estimates measuring these associations is shown in table 3. A significant positive relationship was observed between the number of patients presenting for night-time headaches and mean temperature (relative risk (RR): $1.03,95 \%$ CI 1.01 to 1.05$)$. Subanalysis by sex revealed a significant positive relationship only between the number of patients for night-time headaches and mean temperature among female patients (RR: 1.04, 95\% CI 1.01 to 1.07). Furthermore, we analysed the association between the number of patients for night-time headaches and typhoons. There was no change in the number of patients 3 days before and after typhoon landing (figure 2).

\section{DISCUSSION}

The present study was the first to examine the association between the number of paediatric ED patients with nighttime headaches and exposure to environmental factors, focusing on children. We observed positive relationships 
Table 1 Environmental variables in Kobe, Japan (2011-2019)

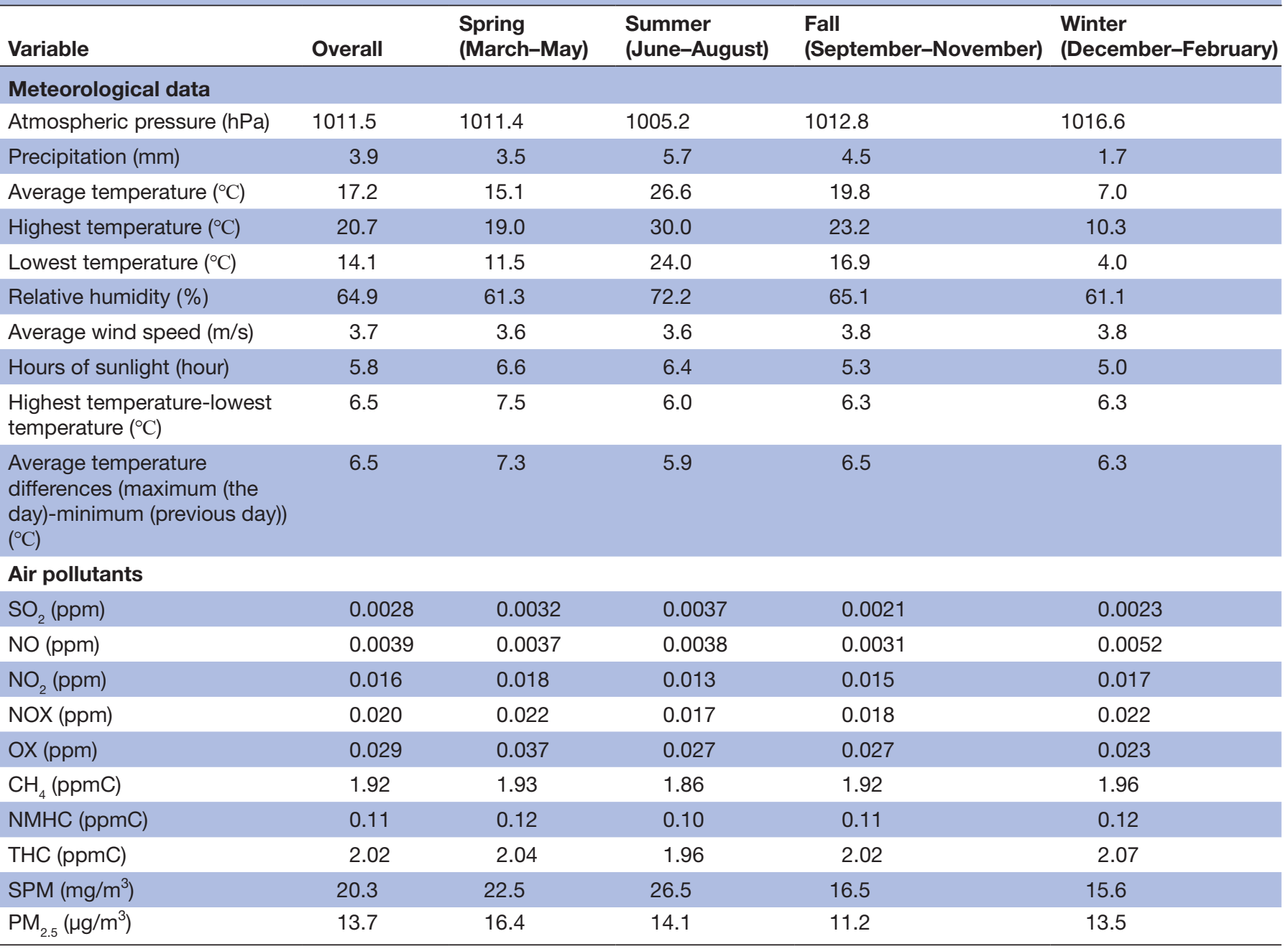

Data are represented as means.

Data are missing at the following dates due to the maintenance of measuring instruments or suspension of measurement due to the construction of the station building:.

$\mathrm{SO}_{2} 4 / 8-11,12 / 23-25 / 2011,2 / 25-26 / 2012,3 / 9-3 / 14 / 2013,1 / 13-19 / 2014 ;$ NO 5/5-28, 6/3-9/11/2013, 1/20-27, 2/1-2, 2/6-9/2014, $12 / 23 / 2015$,.

5/30-6/5, 8/20-9/15, 9/19-29, 11/15, 12/2-12/6, 12/15-20/2016, 9/5-9/11/2017, 9/12-16, 10/1, 12/6-9, 12/17-18, 12/24-30/2018, 2/26, 6/4/2019;

$\mathrm{NO}_{2}$ 5/5-28, 6/4-9/11/2013, 1/20-27, 2/1-2, 2/6-9/2014, 12/23/2015, 5/30-6/5, 8/20-9/15, 9/19-29, 11/15, 12/2-12/6, 12/15-20/2016, $9 / 5-9 / 11 / 2017$

9/12-16, 10/1, 12/6-9, 12/17-18, 12/24-30/2018, 2/26, 6/4/2019; NOX 5/5-28, 6/3-9/11/2013, 1/20-27, 2/1-2, 2/6-9/2014, 12/23/2015,. 5/30-6/5, 8/20-9/15, 9/19-29, 11/15, 12/2-12/6, 12/15-20/2016, 9/5-9/11/2017, 9/12-16, 10/1, 12/6-9, 17-18, 24-30/2018, 2/26, 6/4/2019;

OX 8/20, 11/25-27/2019; $\mathrm{CH}_{4}$ 9/1-2, 11/28/2013, 2/13-16, 7/18-19/2016, 10/4-8/2019; NMHC 9/1-2, 11/28/2013, 2/13-16, 7/1819/2016, 10/4-8/2019;

THC 9/1-2, 11/28/2013, 2/13-16, 7/18-19/2016, 10/4-8/2019; SPM 10/11-14/2013.

$\mathrm{CH}_{4}$, methane; $\mathrm{hPa}$, hectopascal pressure unit; NMHC, non-methane hydrocarbons; NO, nitrogen oxide; NOX, nitrogen oxides; OX, oxidant; $\mathrm{PM}_{25}$, particulate matter $(2.5 \mu \mathrm{m})$; $\mathrm{SO}_{2}$, sulphur dioxide; SPM, suspended particulate matter; THC, total hydrocarbons.

between the number of patients for night-time headaches and mean temperature, especially among female children. No relationships were found between night-time headaches and air pollutants or typhoon landing.

Previous studies have reported an association between air pollutants, such as $\mathrm{SO}_{2}, \mathrm{NO}_{2} \mathrm{CO}, \mathrm{O}_{3}, \mathrm{PMs}$ and headache in all age groups. ${ }^{4-10}$ However, such factors are controversial, and the results of these studies vary among regions. This is probably due to the geographic diversity, complexity of multiple pollutants and other confounders.

Study populations for the previous studies included both adults and children, ${ }^{59}$ and contributing factors for headache, especially in children, were not reported. To the best of our knowledge, there is no extant study on the relationship between air pollution and night-time headache focusing on children. The present study revealed no 


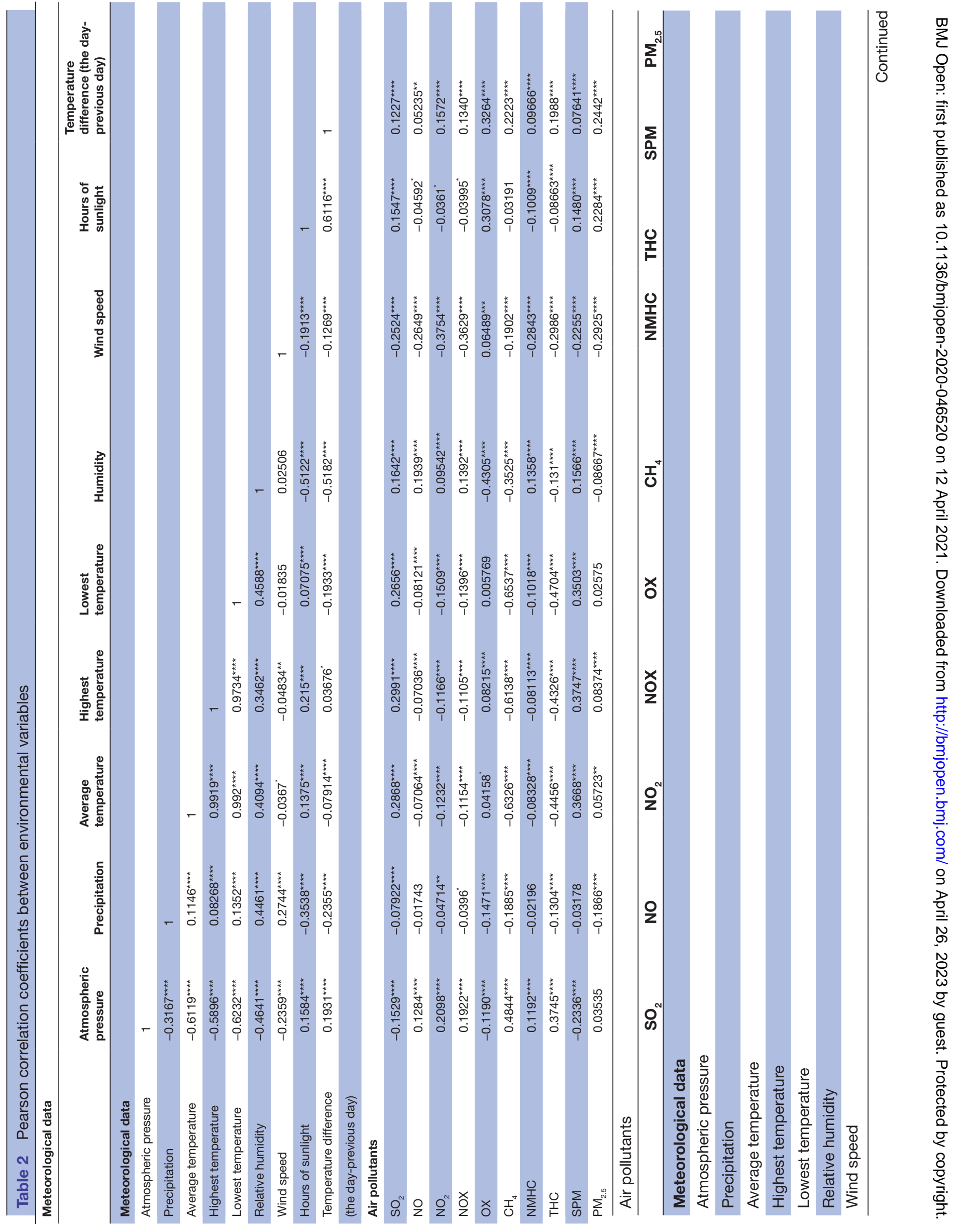




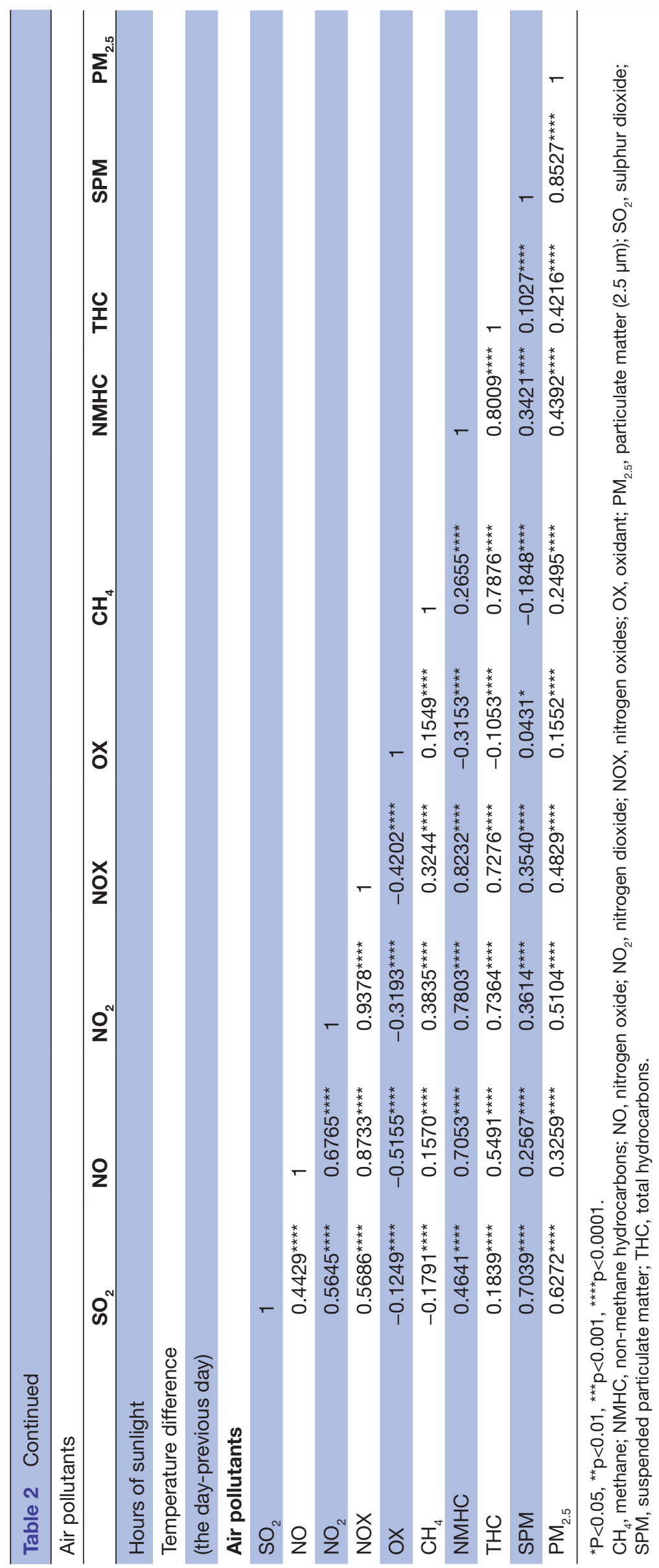

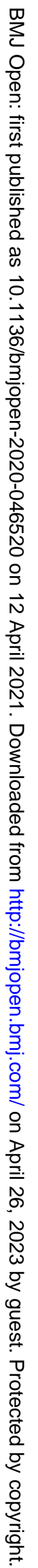




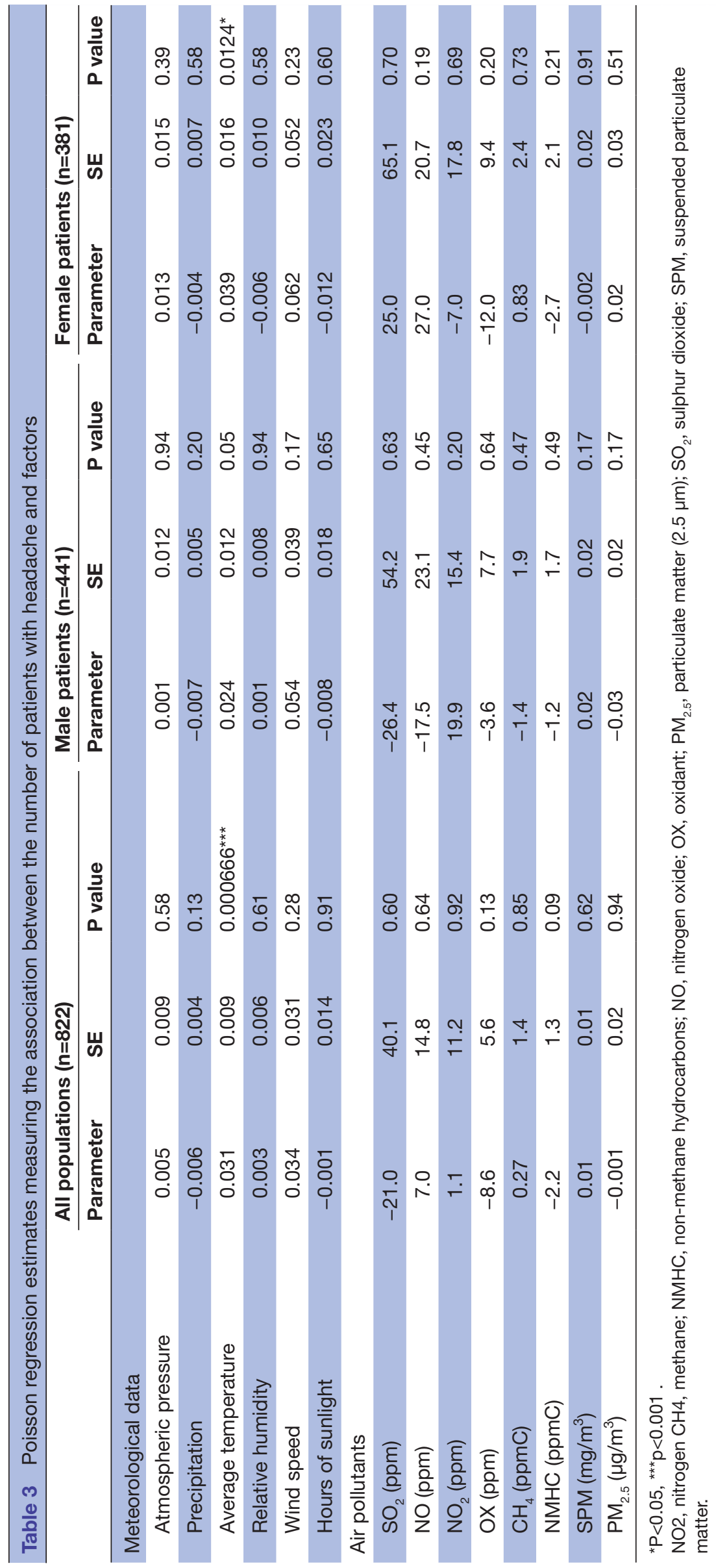




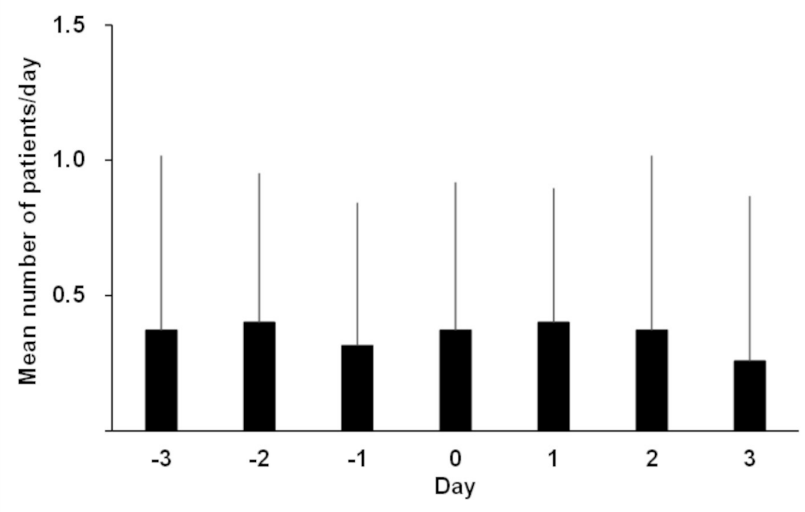

Figure 2 The number of patients presenting with night-time headaches in 3 days before and after the typhoon landing. There was no change in the number of patients for headache in 3 days before and after the event. Data are represented as mean \pm SD.

relationship between the number of patients presenting with night-time headaches and air pollution, although studies involving both adults and children reported the effects of air pollutants and headaches. In the present study, the concentration values of air pollutants were not significantly different from those reported in previous studies. ${ }^{4-7}$ There may be a few reasons for this. First, we hypothesise that sensitivity to air pollutants as a factor for headache among children is lower than among adults. Second, we hypothesise that children in Japan live in environments where the air condition is well controlled due to modern architecture and the widespread use of air conditioners. Therefore, air pollutant factors seem to exert smaller effects on headaches.

Weather parameters, such as ambient temperature, atmospheric pressure, relative humidity and wind speed, have been reported as environmental factors for headache. ${ }^{810-15}$ However, such factors are also controversial, and the results of these studies differ between regions. As far as we know, only one study regarding the relationship between weather and headache focusing on children has been reported. ${ }^{11}$ Pakalnis and Heyer conducted a retrospective study of a seasonal variation in ED visits for headache in 6572 paediatric patients and reported that headache visits increased during the fall season. ${ }^{11}$ They hypothesised that academic stressors and changes in daily schedule may lead to more headaches. Our results demonstrated that the number of patients with nighttime headaches varied distinctly according to seasons with dominant peaks during summer (July in female children, August in male children). In Japan, the typical summer vacation season is from late July to the end of August. Therefore, the reason for the increased number of patients in the summer season in the present study is different from the hypothesis of Pakalnis and Heyer. ${ }^{11}$ We observed significant positive relationships between the number of patients with night-time headaches and mean temperature by multivariate analysis of Poisson regression estimates. Therefore, hot weather itself contributes to headache among paediatric patients. Some studies have revealed a positive relationship between ambient temperature and headache. ${ }^{13141718}$ As far as we know, the pathophysiology of headache and ambient temperature remains unknown. In Kobe, summers include high ambient temperature and relative humidity (table 1), and heatstroke sometimes occurs. Under such conditions, children will experience inhibition of heat dissipation from the skin by evaporative cooling of the skin in hot and humid environments which accelerates dehydration and electrolyte imbalance, and headache may occur due to thermal balance disruption. ${ }^{19}$ Benign exertional headache provoked by sustained exertion, particularly in a hot environment, was reported. ${ }^{20}$ Therefore, the relationship between headaches and ambient temperature is compatible, although the actual pathophysiology is unknown. Further research is needed. Interestingly, our findings indicate that the peak number of female patients presenting for night-time headaches occurred a month earlier than the peak for male patients. During the summer season in Kobe city, the temperature gradually increases from June to August. Female children may be more susceptible to temperature increases.

The present study has several limitations. First, headaches were not classified because there was no headache specialist available in the ED. Therefore, the accurate number of patients with migraine, tension headache, and cluster headache is unknown. Second, our database did not include other background data, such as medical history or medication, making analyses of these factors impossible. Third, regarding air pollutants, data from only one centre (the most stable measurement in the city) was chosen, and it may differ from the actual home and school environment of patients. In addition, we were unable to analyse other factors, such as $\mathrm{O}_{3}$ or $\mathrm{CO}$, which were previously reported to be related to headache. Finally, our study aimed to elucidate the association between the number of patients with a chief complaint of headache and the environment. Therefore, we lack information regarding any patients who experienced headaches but did not visit our centre. Although our study has some limitations, its strengths include the relatively long (for 9 years) study period and large sample size (approximately 800 consecutive children out of more than 265 000) were included.

In conclusion, the present study is the first to examine the association between night-time headaches in children and exposure to environmental factors (meteorological factors, air pollution and typhoon) after controlling for confounding factors. Our results suggest that preventive measures against night-time headaches may be possible by reducing time spent outside during the summer.

Acknowledgements We thank the Clinical and Translational Research Center at Kobe University for the statistical analyses of the data.

Contributors HY: conceptualisation, methodology, formal analysis, investigation and writing the original draft. KN: conceptualisation, methodology, formal analysis, investigation, writing the original draft and supervision. Sl: conceptualisation, 
methodology, formal analysis, and investigation. HN: writing (review and editing) and supervision. TN: writing (review and editing) and supervision. CN: writing (review and editing) and supervision. HT: writing (review and editing) and supervision. AU: writing (review and editing) and supervision. Kls: writing (review and editing) and supervision. IM: writing (review and editing) and supervision. Kli: writing (review and editing) and supervision. Al: resources, writing (review and editing) and supervision. All authors have read and approved the final manuscript.

Funding The authors have not declared a specific grant for this research from any funding agency in the public, commercial or not-for-profit sectors.

Competing interests None declared.

Patient consent for publication Not required.

Ethics approval This retrospective, clinical observational time-series analysis study was conducted under the approval of the Ethics Committee of Kobe Children's Primary Emergency Medical Center (ID:2020-4), with a waiver for informed consent, given the retrospective nature of the study and accessibility to the public using our homepage.

Provenance and peer review Not commissioned; externally peer reviewed.

Data availability statement Data are available on reasonable request. Data are not publicly available. However, data may be obtained by reasonable request from the corresponding author.

Open access This is an open access article distributed in accordance with the Creative Commons Attribution Non Commercial (CC BY-NC 4.0) license, which permits others to distribute, remix, adapt, build upon this work non-commercially, and license their derivative works on different terms, provided the original work is properly cited, appropriate credit is given, any changes made indicated, and the use is non-commercial. See: http://creativecommons.org/licenses/by-nc/4.0/.

\section{ORCID iDs}

Hiroshi Yamaguchi http://orcid.org/0000-0002-0787-964X

Kandai Nozu http://orcid.org/0000-0002-0290-3137

Ichiro Morioka http://orcid.org/0000-0002-5685-2670

\section{REFERENCES}

1 Sheridan DC, Meckler GD, Spiro DM, et al. Diagnostic testing and treatment of pediatric headache in the emergency department. $J$ Pediatr 2013;163:1634-7.

2 Abu-Arafeh I, Razak S, Sivaraman B, et al. Prevalence of headache and migraine in children and adolescents: a systematic review of population-based studies. Dev Med Child Neurol 2010;52:1088-97.
3 Perry MC, Yaeger SK, Toto RL, et al. A modern epidemic: increasing pediatric emergency department visits and admissions for headache. Pediatr Neurol 2018;89:19-25.

4 Chiu H-F, Weng Y-H, Chiu Y-W, et al. Air pollution and daily clinic visits for headache in a subtropical city: Taipei, Taiwan. Int J Environ Res Public Health 2015;12:2277-88.

5 Szyszkowicz M, Stieb DM, Rowe BH. Air pollution and daily ED visits for migraine and headache in Edmonton, Canada. Am J Emerg Med 2009;27:391-6.

6 Szyszkowicz M, Kaplan GG, Grafstein E, et al. Emergency department visits for migraine and headache: a multi-city study. Int $J$ Occup Med Environ Health 2009;22:235-42.

7 Dales RE, Cakmak S, Vidal CB. Air pollution and hospitalization for headache in Chile. Am J Epidemiol 2009;170:1057-66.

8 Vodonos A, Novack V, Zlotnik Y, et al. Ambient air pollution, weather and daily emergency department visits for headache. Cephalalgia 2015;35:1085-91.

9 Szyszkowicz M, Rowe BH, Kaplan GG. Ambient sulphur dioxide exposure and emergency department visits for migraine in Vancouver, Canada. Int J Occup Med Environ Health 2009;22:7-12.

10 Szyszkowicz M. Air pollution and daily emergency department visits for headache in Montreal, Canada. Headache 2008;48:417-23.

11 Pakalnis A, Heyer GL. Seasonal variation in emergency department visits among pediatric headache patients. Headache 2016;56:1344-7.

12 Yang AC, Fuh J-L, Huang NE, et al. Patients with migraine are right about their perception of temperature as a trigger: time series analysis of headache diary data. J Headache Pain 2015;16:533.

13 Prince PB, Rapoport AM, Sheftell FD, et al. The effect of weather on headache. Headache 2004;44:596-602.

14 Mukamal KJ, Wellenius GA, Suh HH, et al. Weather and air pollution as triggers of severe headaches. Neurology 2009;72:922-7.

15 Cooke LJ, Rose MS, Becker WJ. Chinook winds and migraine headache. Neurology 2000;54:302-7.

16 Kanda $Y$. Investigation of the freely available easy-to-use software 'EZR' for medical statistics. Bone Marrow Transplant 2013;48:452-8.

17 Tanik N, Saçmaci H, Aktürk T. The relationship between exposure to hot/cold weather and the clinical features of headaches in patients with migraine and tension-type headaches. Neurol Res 2020;42:239-43.

18 Yilmaz M, Gurger M, Atescelik M, et al. Meteorologic parameters and migraine headache: ED study. Am J Emerg Med 2015;33:409-13.

19 Mutic AD, Mix JM, Elon L, et al. Classification of heat-related illness symptoms among Florida Farmworkers. J Nurs Scholarsh 2018;50:74-82.

20 Classification and diagnostic criteria for headache disorders, cranial neuralgias and facial pain. headache classification Committee of the International headache Society. Cephalalgia 1988;8 Suppl 7:1-96. 